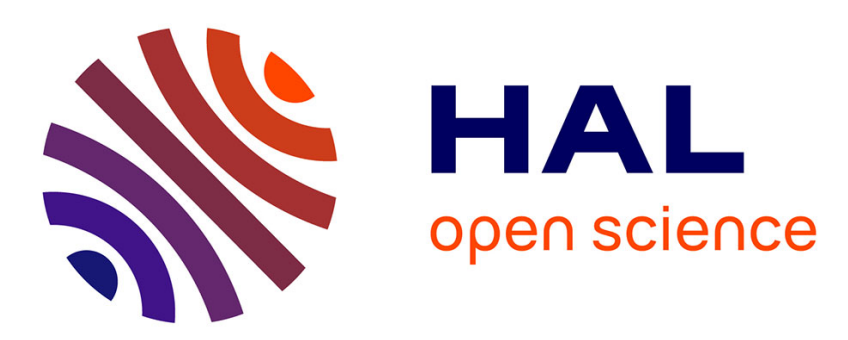

\title{
Thermogravimetric experiments coupled with acoustic emission analysis dedicated to high-temperature corrosion studies
}

Omar Al Haj, Véronique Peres, Eric Serris, François Grosjean, Jean Kittel, Francois Ropital, Michel Cournil

\section{To cite this version:}

Omar Al Haj, Véronique Peres, Eric Serris, François Grosjean, Jean Kittel, et al.. Thermogravimetric experiments coupled with acoustic emission analysis dedicated to high-temperature corrosion studies. Sensor letters, 2014, 12 (10), pp.1488-1494. 10.1166/sl.2014.3332 . hal-01096453

\section{HAL Id: hal-01096453 https://hal.science/hal-01096453}

Submitted on 17 Dec 2014

HAL is a multi-disciplinary open access archive for the deposit and dissemination of scientific research documents, whether they are published or not. The documents may come from teaching and research institutions in France or abroad, or from public or private research centers.
L'archive ouverte pluridisciplinaire HAL, est destinée au dépôt et à la diffusion de documents scientifiques de niveau recherche, publiés ou non, émanant des établissements d'enseignement et de recherche français ou étrangers, des laboratoires publics ou privés. 


\title{
Thermogravimetric experiments coupled with acoustic emission analysis
}

\section{dedicated to high-temperature corrosion studies on metallic alloys}

\author{
AL HAJ Omar ${ }^{\mathrm{a}}$, PERES Véronique ${ }^{\mathrm{a}^{*}}$, SERRIS Eric $^{\mathrm{a}}$, GROSJEAN François $^{\mathrm{b}}$, KITTEL Jean $^{\mathrm{b}}$, \\ ROPITAL François ${ }^{\mathrm{b}}$, COURNIL Michel $^{\mathrm{a}}$ \\ ${ }^{a}$ Ecole Nationale Supérieure des Mines, SPIN-EMSE, Département PRESSIC, CNRS:UMR 5307, LGF, 42023 \\ Saint-Etienne France, \\ ${ }^{\mathrm{b}}$ IFP Energies nouvelles, Rond-point de l'échangeur de Solaize BP3, 69360 Solaize France.
}

\section{Abstract}

High temperature corrosion of metallic alloys in industrial equipments, such as refinery and petrochemical equipments concerns several phenomena: oxidation, carburization...

These phenomena can create stresses in the materials, the relaxation of which mostly produces transient elastic waves.

Several methods enable the recording and analyzing of these transient elastic waves. Piezoelectric sensors fixed directly on the sample can record elastic waves with a low decrease in energy and frequency at ambient temperature. In case of high temperature environments, a waveguide can also be used to transmit waves from sample to sensors. For this purpose, alumina or platinum are mainly used as waveguide materials.

The goal of this study is to assign the acoustic signals to the corrosion phenomena and establish an acoustic signals database. This database will then be useful for the monitoring of industrial equipment using acoustic emission methods. For this purpose, thermogravimetric analysis (TGA) has been coupled with acoustic emission (AE) devices. Simultaneous measurements of the mass variation and of the acoustic signals emitted during the oxidation of samples of the zirconium based alloy, Zircaloy-4, at high temperature $900{ }^{\circ} \mathrm{C}$ can provide complementary information to increase the level of understanding of high temperature 
corrosion mechanisms. Our work focuses on a specific waveguide (WG) conception and on the transmission of elastic waves (acoustic signals) through the waveguide at high temperature. Results on experiments concerning the corrosion of zirconium alloy plates under oxidizing atmosphere are presented.

Keywords: Thermogravimetric analysis, Acoustic emission, High temperature corrosion, Waveguide, Elastic waves.

\section{Introduction}

Iron, nickel, cobalt alloys are broadly used as reactor or container materials in several industrial domains (refinery, petrochemical ...). To be able to control the level of damage of these equipments in service represents a major challenge [1]. Corrosion of iron based alloys becomes significant at high temperatures $\left(400{ }^{\circ} \mathrm{C}-900{ }^{\circ} \mathrm{C}\right)$. In order to quantify the level of damage of these alloys, acoustic emission seems to be an interesting method owing to its sensitivity and its non-destructive aspect. AE does neither require ultrasonic signal exciters, nor a heavy infrastructure. The implementation cost of AE systems remains moderate. Acoustic emission measurements can be applicable to equipment in service under various environmental conditions.

This technique has been used to investigate the behavior of different materials at high temperature. Ferrer and al. [2] studied the effect of dimethyl disulfide (DMDS) on the inhibition of the attacks by metal dusting on Incolloy 800 tubes by means of acoustic emission. Acoustic emission experiments were also performed by Schulte and al. [3] to evaluate the sulfidation of ferritic and austenitic steels. Bennett and al. [4] mounted an acoustic emission device into a thermobalance. Works were also carried out by Schmutzler and al. [5] to study the oxidation mechanisms of Fe-Cr-Al by coupling TGA and AE. More 
recently, Tran and al. [6] also studied the oxidation of titanium, zirconium, nickel and chromium pure metals in a tubular furnace instrumented with an acoustic emission device.

High temperature corrosive phenomena create stresses in the materials; the relaxation of these stresses produces transient elastic waves which can be recorded and analyzed using the AE system. The study of these transient waves enables the anticipation of the degree of damage of these alloys [1]. Several methods are used to record and analyze these transient elastic waves. At ambient temperature, piezoelectric sensors in contact with the sample can record an important number of elastic waves with a low attenuation of the signal energy $[7,8]$. At high temperature, waveguides are used to transmit the waves from the sample to the sensors; the waveguide design depends on several factors, like wave propagation velocity, wave damping, waveform conservation, experimental atmosphere and temperature. Alumina and platinum are mainly used as waveguide materials [9]; these materials reduce the amplitude and the energy of the signals but they conserve the waveforms [10].

The aim of our study is to associate the elastic waves with the corrosion phenomena in order to be able to monitor the industrial equipment using acoustic emission method. For this purpose thermogravimetric analysis has been coupled with acoustic emission devices to measure acoustic signals emitted during the corrosion of samples at high temperature [11]. Simultaneous measurements of the mass variation and of the acoustic signals can give additional information to increase the level of understanding of high temperature corrosion mechanisms. This work focuses on the transmission of the acoustic signals via the waveguide at ambient temperature and at high temperature. The selection of the waveguide was applied according to several criteria; one of them is the resistance under corrosive atmosphere. For this purpose, a long waveguide was manufactured in alumina, a material which presents a chemical inertness towards the samples and the different atmospheres. In order to validate the transmission of the waves from the sample to the sensors via the alumina waveguide, two 
tests were performed. The first test, based on the normalized Hsu-Nielsen method, was carried out at ambient temperature. The second test was executed at high temperature using the oxidation of zirconium alloy plates under oxidizing atmosphere at $900{ }^{\circ} \mathrm{C}$ to create cracks and thus elastic waves.

\section{Experimental methods}

\section{II.1 Thermogravimetric analyzer}

Thermogravimetric analysis coupled with the acoustic emission principle was developed in 1977 by R.F. Hochman [12], and then used by H.J. Grabke [13] and more recently by F. Ropital $[14,15]$. The experiment consists in positioning a sample on a waveguide inside the TGA furnace and record simultaneously the mass variation and the AE signals using piezoelectric sensors placed in the cold part of the TGA.

In our study, experiments were carried out on a symmetric thermobalance (SETARAM TGA 24) at $900{ }^{\circ} \mathrm{C}$ at atmospheric pressure (1 atm) with a gas flow rate of $3 \mathrm{~L} / \mathrm{h}$. The TGA equipment is constituted of two symmetric parts; one is used for the sample, whereas the other one is used as a reference. Both parts include a furnace consisting of a graphite resistor which enables to be heated up to $1600{ }^{\circ} \mathrm{C}$. The resistor is protected from oxidation by an internal dense alumina tube and by a steady flow of argon. Thermocouples (PtRh $6 \%$ / PtRh $30 \%$ ) record the temperature in each furnace. Gases can be analyzed at the TGA outlet using a mass spectrometry analyzer, a humidity sensor or an oxygen sensor.

Piezoelectric sensors should be placed as close as possible to the source of the acoustic emission but in the cold part of the TGA on the top of the waveguide. The received signal is pre-amplified and subsequently processed using the acquisition system of the AE (Fig. 1). 


\section{II.2 Acoustic emission}

When materials undergo local plastic deformation, cracking or volume transformation, abrupt variations of the field stress take place. This variations lead to elastic energy relaxation. The abrupt release of energy stored in a delimited source region generates high frequency elastic waves $(10-1000 \mathrm{kHz})$ called acoustic emission (AE) [16,17]. Crack formation, grain rearrangement, friction between solid surfaces and other grain-scale motions are typical processes which can produce AE. High temperature corrosive phenomena as the growth of oxide layers or the chemical reduction of protective oxides $\left(\mathrm{Al}_{2} \mathrm{O}_{3}, \mathrm{Cr}_{2} \mathrm{O}_{3}\right)$ can also produce elastic waves which propagate through the bulk of the material as well as on the surface of the material. Piezoelectric sensors are used to convert these mechanical waves into electric signals.

Discontinuous acoustic emission control (AE burst) has been used during our experimental tests. This method is applicable when elastic waves energy are located in the range of $10^{-11} \mathrm{~J}$ to $10^{-4} \mathrm{~J}$. The waveform of the acoustic signals is similar to damped waves form. It is necessary to choose adequate AE burst parameters (Table 1) in order to analyze the acoustic emission signals. An AE burst starts when the signal amplitude exceeds the prescribed threshold (this threshold may be fixed or self-adjusting to the noise level). Further analysis can give more information about the recorded AE signals.

The parameters monitored (counts, amplitude, absolute energy, average frequency...) depend on the objective of each study. For example there may be a close relation between the burst amplitude and the level of damage of the material $[18,19]$.

The main parameters used in this study are: 
- Burst amplitude: the maximum amplitude reach during an $\mathrm{AE}$ burst $\left(\mathrm{dB}_{\mathrm{AE}}\right)$;

- Burst duration: the time difference between the first and the last threshold crossing $(\mu \mathrm{s})$

- Counts: the number of threshold crossing during an AE burst;

- Rise time: the time difference from the first threshold crossing to the burst amplitude $(\mu \mathrm{s})$;

- Absolute energy: integration of the square of the signal deviation from its average: $\operatorname{Eabs}(\mathrm{T})=\int_{T}\left|A^{2}\right| d t n$ Absolute energy unit is attojoule $\left(1 \mathrm{aJ}=10^{-18} \mathrm{~J}\right)$;

- Average frequency: a calculated feature obtained from (Count) divided by (Duration), which determines an average frequency over one AE burst $(\mathrm{kHz})$.

In order to record the acoustic signals emitted during the TGA experiments, a specific acoustic device has been developed (transducer, waveguide, acquisition chain) (fig. 1). AE sensors were placed inside the cold part of the balance where the temperature does not exceed $150{ }^{\circ} \mathrm{C}$. The sensors are linked to an acquisition chain controlled by the AEwin ${ }^{\mathrm{TM}}$ software provided by the Physical Acoustics Corporation Company. Data were analyzed using Noesis ${ }^{\mathrm{TM}}$ software provided by the same company. The characteristics of the acquisition chain are given in Table 1.

\section{II.3 Waveguide tests}

Our work focuses on a specific wave guide (WG) conception and on its implementation in a TGA device. The waveguide was chosen according to the following criteria: i) chemical resistance against corrosive environments (oxygen or carbon-reductive atmospheres); ii) chemical inertness with regard to the alloy samples; iii) good transmission of the acoustic 
signals via the waveguide (low attenuation of the signal energy). Following these requirements, a long waveguide was designed in alumina. Its conception was limited by the internal diameter of the alumina tube $(2 \mathrm{~cm})$ and by the maximal weight that can be supported by the balance $(10 \mathrm{~g})$. Samples were placed on a specific support to optimize the contact between the sample and the surface of the waveguide.

At ambient temperature, the normalized Hsu-Nielsen test (AFNOR NF EN 1330-9) was carried out to verify the AE system. This test simulates an acoustic emission event by breaking a $0.5 \mathrm{~mm}$ pencil lead tip against the sample surface. This generates an intense acoustic signal, quite similar to a natural AE source that the sensors detect as a strong burst. Generally, the lead breaks should generate amplitudes of at least $80 \mathrm{~dB}_{\mathrm{AE}}$ for a reference voltage of $1 \mathrm{mV}$ and a total system gain of $80 \mathrm{~dB}_{\mathrm{AE}}$.

The signals amplitude resulting from our test amounts to $90 \mathrm{~dB}_{\mathrm{AE}}$. These results confirm the good transmission of the acoustic signals via the waveguide at ambient temperature.

In order to verify the transmission of elastic waves (acoustic signals) through the waveguide at high temperature, we developed a reference test using the corrosion of zirconium alloy plates (Zircaloy-4) under oxidizing atmosphere $\left(75 \% \mathrm{He}+20 \% \mathrm{O}_{2}+5 \%\right.$ Air) at high temperature $\left(900{ }^{\circ} \mathrm{C}\right)$. Oxidation mechanism of this alloy in such conditions is well described $[6,20,21]$. The oxidation of the Zircaloy-4 is characterized by an inward oxide layer $\left(\mathrm{ZrO}_{2}\right)$ growth on the sample surface. The growth of $\mathrm{ZrO}_{2}$ layer is associated with a volume increase. The Pilling-Bedworth ratio $\left(\mathrm{R}_{\mathrm{PB}}\right)$ makes a comparison between the oxide molar volume $\left(\mathrm{V}_{\mathrm{Zr}_{2}} \mathrm{O}_{2}\right)$ and the corresponding metal molar volume $\left(\mathrm{V}_{\mathrm{Zr}}\right)$.

$$
\mathrm{R}_{\mathrm{PB}}=\frac{\mathrm{VZrO}}{\mathrm{VZr}}=1.56
$$

A $R_{P B}$ value higher than unity means that the oxide layer is exposed to compressive stresses. When these stresses exceed the zirconia fracture resistance $\left(\sigma>\sigma_{f}\right)$, cracks occur in 
the oxide layer and emit AE signals. The record of a significant number of AE signals during this control test may then validate the transmission of acoustic signals through our waveguide at high temperature.

\section{Results and discussion}

The experiments were performed on rectangular Zircaloy-4 specimens $(4.8 \mathrm{~mm}$ x $4.6 \mathrm{~mm} \mathrm{x}$ $0.5 \mathrm{~mm})$. The chemical composition of this material is presented in Table 2.

Thermogravimetric analyses were performed at $900{ }^{\circ} \mathrm{C}$ under a mixed gas atmosphere $\left(75 \% \mathrm{He}+20 \% \mathrm{O}_{2}+5 \%\right.$ Air) introduced by two flow meters with a total gas flow rate of $3 \mathrm{~L} / \mathrm{h}$ at atmospheric pressure $(1 \mathrm{~atm})$. The heating-up $(15 \mathrm{~K} / \mathrm{min})$ to $900{ }^{\circ} \mathrm{C}$ was made under helium. Once the isothermal and isobaric conditions have been attained, the gas mixture $\left(75 \% \mathrm{He}+20 \% \mathrm{O}_{2}+5 \%\right.$ Air) was introduced for 3 hours. The cooling $(15 \mathrm{~K} / \mathrm{min})$ was done under the same process gas mixture. The $\mathrm{AE}$ threshold has been fixed to $30 \mathrm{~dB}_{\mathrm{AE}}$.

Blank tests without any specimen were carried out in order to check if the waveguide did not significantly react with the gas mixture. During these tests, the stability of the mass signal validates the chemical inertness of the waveguide. The acoustic signals recorded during the blank tests result from the instrumental noise (IN). The characteristics of these AE signals are given in Table 3 .

The mass variation of a Zircaloy-4 sample during the oxidation test, mass normalized with regard to the sample surface, as a function of temperature and time is presented in Figure 2. There is a small decrease in mass during the heating up which is due to the non-symmetric aspect between the two parts of the thermobalance (fig.1). A fluctuation of the mass variation can be observed after the introduction of the oxidant gas mixture (3500 s). A significant increase of the mass gain is observed during the high-temperature dwell under oxidizing 
atmosphere. An acceleration of the mass gain rate is observed after $5000 \mathrm{~s}$ due to the breakaway which is a kinetic transition. The breakaway corresponds to the cracking of the primary dense thin layer of $\mathrm{ZrO}_{2}$ leading to a free access for oxygen to the metal oxide interface. After the breakaway the oxidation process is enhanced. The mass gain corresponds to the growth of the oxide layer $\left(\mathrm{ZrO}_{2}\right)$ on the sample surface.

As predicted in paragraph III, this phenomenon is accompanied by acoustic emission signals. The AE activity, six times higher than the blank test activity at the end of the dwell time, increases during the growth of the oxide layer (Fig. 3). According to the graph showing the mass gain rate variation as function of time (Fig. 3), we note that the breakaway occurs after $5000 \mathrm{~s}$. This phenomenon is accompanied by change in the slope of the curve of the cumulative counts (C.C.) during the oxidation test. The wave transmission from the sample to the sensors via the alumina waveguide at high temperatures has been validated by this test.

$\mathrm{AE}$ analysis of the data recorded during the oxidation test of Zircaloy-4 reveals the presence of three populations of acoustic signals. The parameters of each population are presented in Table 3. Signals assigned to the instrumental noise (IN) are characterized by a very short duration and a low counts' number, $95 \%$ of bursts of this population are characterized by $(1$ count $-1 \mu \mathrm{s})$. These signals are also recorded throughout the blank test. Bursts recorded during the dwell time and the cooling are absent during the blank test carried out without any sample. These signals are really linked to the sample oxidation process. Bursts recorded during the dwell time are characterized by mean amplitudes in the range of $(32-55) \mathrm{dB}_{\mathrm{AE}}$ as can be seen in Figure 4, a high counts' number (tens of counts per burst) and a high absolute energy $(1-2000 \mathrm{aJ})$. During cooling, bursts of very high energy are recorded. They are characterized by a counts' number in the order of magnitude of hundreds of counts per burst, a long duration (thousands of $\mu$ s per burst), a high amplitude varying between $55 \mathrm{~dB}_{\mathrm{AE}}$ and $75 \mathrm{~dB}_{\mathrm{AE}}$ (as shown in Figure 4), and a very high absolute energy 
$\left(2 \times 10^{5} \mathrm{aJ}\right)$. The analysis of the average frequency of the acoustics bursts during the oxidation treatment (Fig. 5) shows that AE signals recorded during dwell time and cooling steps possess a low average frequency varying between $0 \mathrm{kHz}$ and $200 \mathrm{kHz}$. The corresponding signals assigned to the instrumental noise are characterized by a high average frequency in the range of $200 \mathrm{kHz}$ and $1000 \mathrm{kHz}$ including the resonance frequency of the sensors $(300 \mathrm{kHz})$.

The knowledge of Zircaloy-4 oxidation mechanism at $900{ }^{\circ} \mathrm{C}$ under oxidizing atmosphere allows us to assign these AE bursts to the physical phenomena which represent the source of emission of these AE bursts. Cracks have appeared during the high-temperature dwell mainly due to the compressive stresses inside the zirconia layer. Furthermore, cracks have appeared during the cooling stage due to the difference in thermal expansion coefficient between the metal and the oxide. SEM pictures of post-mortem oxidized samples (Fig. 6) indicate that cracks are located inside the thick zirconia layer parallel to the metal oxide interface or perpendicular to this interface. The large perpendicular cracks are normally related to the difference in thermal expansion coefficient appearing during the cooling.

In order to attribute the acoustic bursts to the different kinds of cracks (parallel or perpendicular cracks), a detailed $\mathrm{AE}$ analysis of the waveform (WF) and of the wavelet transform (WT) was carried out on numerous bursts in the dwell part of the treatment and in the cooling part. Figure 7 presents an example of this treatment. The wavelet transform analysis of AE signals recorded during the high-temperature dwell time (Fig. 7a) possesses an acoustic signature different from the AE signals recorded during the cooling (Fig. 7b). The first wavelet transform is mainly punctual while the second one is more continuous (with some spots).

Combining the wavelet transform analysis as well as the quantitative $\mathrm{AE}$ analysis (cumulative count number, amplitude analysis, average frequency analysis) with the SEM observation of post mortem oxidized sample, we can assign the AE bursts to the different 
cracks. Oxidation cracks are numerous and they are parallel to the metal oxide interface. The AE signals associated with this phenomenon are numerous and their energy is of medium order of magnitude. Cracks due to cooling are less frequent but characterized by highly energetic bursts.

\section{Conclusion}

Thermogravimetric experiments coupled with acoustic emission analysis are an interesting way to improve knowledge on the corrosion of metallic materials at high temperature. In such experimental systems, an important aspect is the transmission of acoustic emission signals from the specimen to the sensors in the elevated temperature range. Furthermore, this waveguide shall not disturb the mass gain measurements.

The oxidation of the zirconium alloy induces the growth of a zirconia layer on the material surface. The $\mathrm{ZrO}_{2}$ layer is subjected to compressive stresses which induce internal cracks. These numerous cracks, parallel to the metal oxide interface, are observed on post-mortem oxidized samples. During the isothermal treatment, the cracks are pointed out by numerous specifics acoustic signals of medium energy. Fewer large transversal cracks are also observed in the oxide layer on post-mortem samples. They are mainly due to the cooling, and the AE signals related to this phenomenon are characterized by a high energy and long durations.

The recording of numerous bursts during the oxidation test of Zircaloy-4, and furthermore, the correlation of population of signals to different cracking phenomena validated the alumina waveguide design.

Thermogravimetric experiments coupled with acoustic emission analysis using this alumina waveguide will be used to study the metal dusting corrosion of iron based alloys under carbon rich atmosphere. 


\section{References:}

1. K. Ono, Acoustic emission, Encyclopedia of acoustics, Wiley, (1997)

2. F. Ferrer, J. Goudiakas, E. Andres and C. Brun, Nace Corrosion Conference, (2001) paper 01386

3. M. Schulte, A. Rahmel and M. Schutze, Oxidation of metals, (1998), Vol. 49, p. 33

4. M. J. Bennett, D. J. Buttle, P. D. Colledge, J. B. Price, C. B. Scruby and k. A. Stacey, Materials Science and Engineering (1989), A120 199

5. H. J. Schmutzler and H. J. Grabke, Oxidation of metals (1992), Vol. 39, pp. 15 - 29

6. M. T. Tran, M. Boinet, A. Galerie, Y. Wouters, Corrosion Science (2010), Vol. 52, pp. 2365 2371

7. M. Shuthe, A. Rahmel and M. Shütze, The sulfidation behavior of several commercial Ferritic and Austenitic steels, Oxidation of metals (1998), pp. 33-70

8. Y. C. Zhou, T. Hashida, Thermal fatigue failure induced by delamination in thermal barrier coating, International Journal of Fatigue (2002), Vol. 24, pp. 407-417

9. D. Renusch, M. Schütze, Measuring and modeling the TBC damage kinetics by using acoustic emission analysis, Surface \& Coatings Technology (2007), Vol. 202, pp. 740-744

10. J. Sikorska, J. Pan, The effects of waveguide material and shape on AE transmission characteristics part 1: Traditional features, Journal Acoustic Emission (2004), Vol. 22, pp. $264-273$

11. F. Grosjean, J. Kittel, F. Ropital, E. Serris, V. Peres, Coupling of thermogravimetric and acoustic emission technics for high temperature corrosion studies, Spectra Analyse (2011), Vol. 279, pp. 35-44

12. R. F. Hochman, Proc. of the symp. On Properties of High Temperatures Alloys with Emphasis on Environnemental Effects (Eds. Z. A. Foroulis and F. S. Pettit). The Electrochemical Society (1977), p. 715

13. H. J. Grabke, Materials and Corrosion (1998), Vol. 49, 303 
14. F. Ropital, P. Dascotte, P. Marchand, T. Faure, J. C. Lenain, A. Proust Coupling Thermogravimetric and Acoustic Emission measurements : its application to study the inhibition of catalytic coke deposition, Eurocorr (2004), p. 261

15. F. Ropital, Corrosion et dégradation des matériaux métalliques compréhension des phénomènes et application dans l'industrie pétrolière et des procédés, préfacé par Yves Chauvin, Editions Technip, Paris (2009), pp. 73-79

16. O. Golan, A. Arbel, D. Eliezer, D. Moreno, Mater. Sci. Eng. A A216 (1996), p.125

17. D. Lockner, The role of acoustic emission in the study of rock fracture, International Journal of Rock Mechanics and Mining Sciences \&Geomechanics Abstracts (1993), Vol. 30, pp. 883-899

18. M. Shaira, N. Godin, P. Guy, L. Vanel, J. Courbon, Materials Science and Engineering (2008), Vol. A 492, pp. 392-399

19. A. Marec, Materials and Corrosion (1998), Vol. 49, p. 303

20. M. Tupin, M. Pijolat, F. Valdivieso, M. Soustelle, Journal of Nuclear Materials (2005), Vol. 342 , pp. $108-118$

21. G. Moulin, R. ElTahhan, J. Favergeon, M. Bigerelle, M. Viennot, Journal of Nuclear Materials (2007), Vol. 362, pp. 309-315 


\section{Figures:}

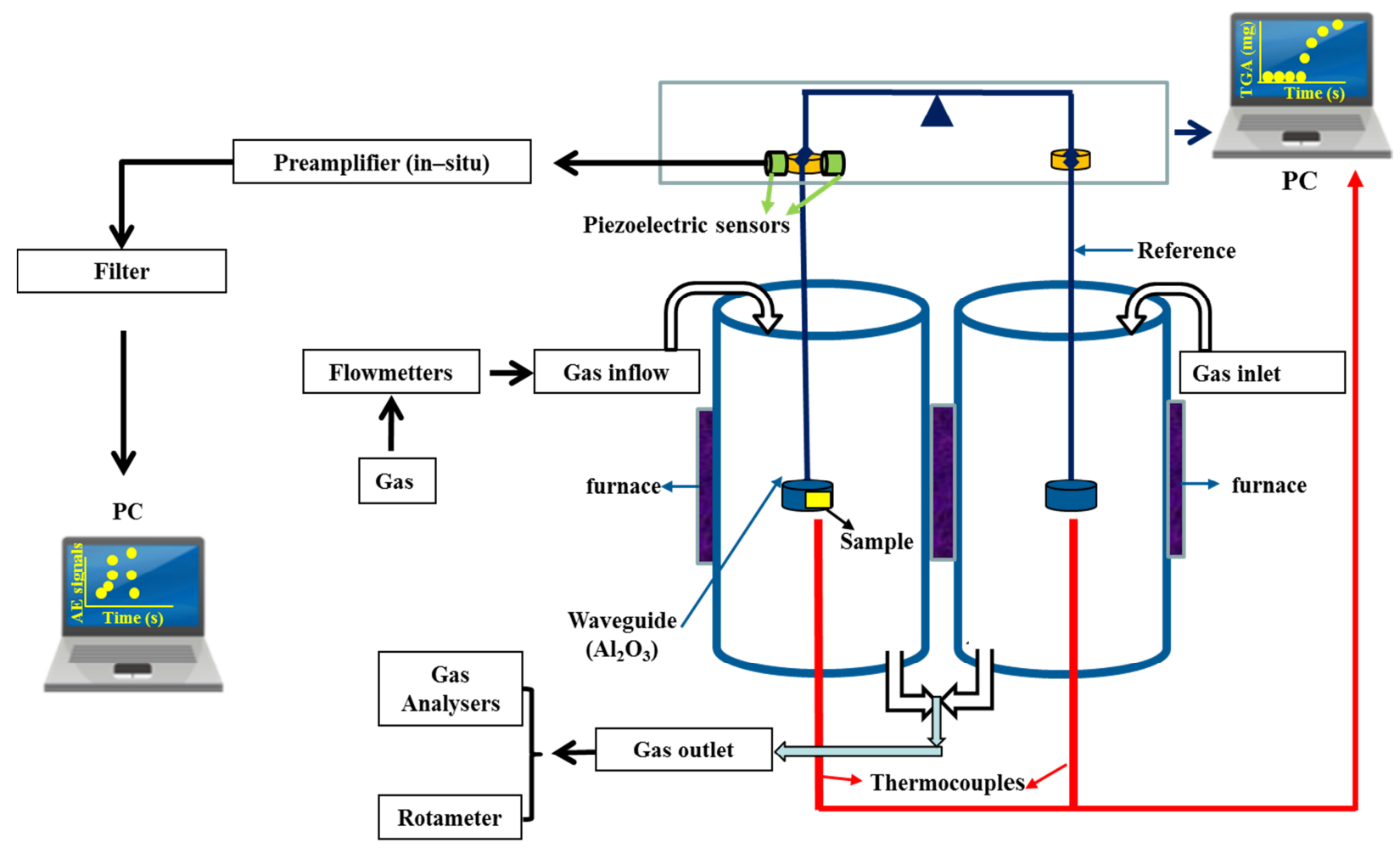

Fig.1. AE acquisition system inside the symmetric thermobalance (TGA 24) 


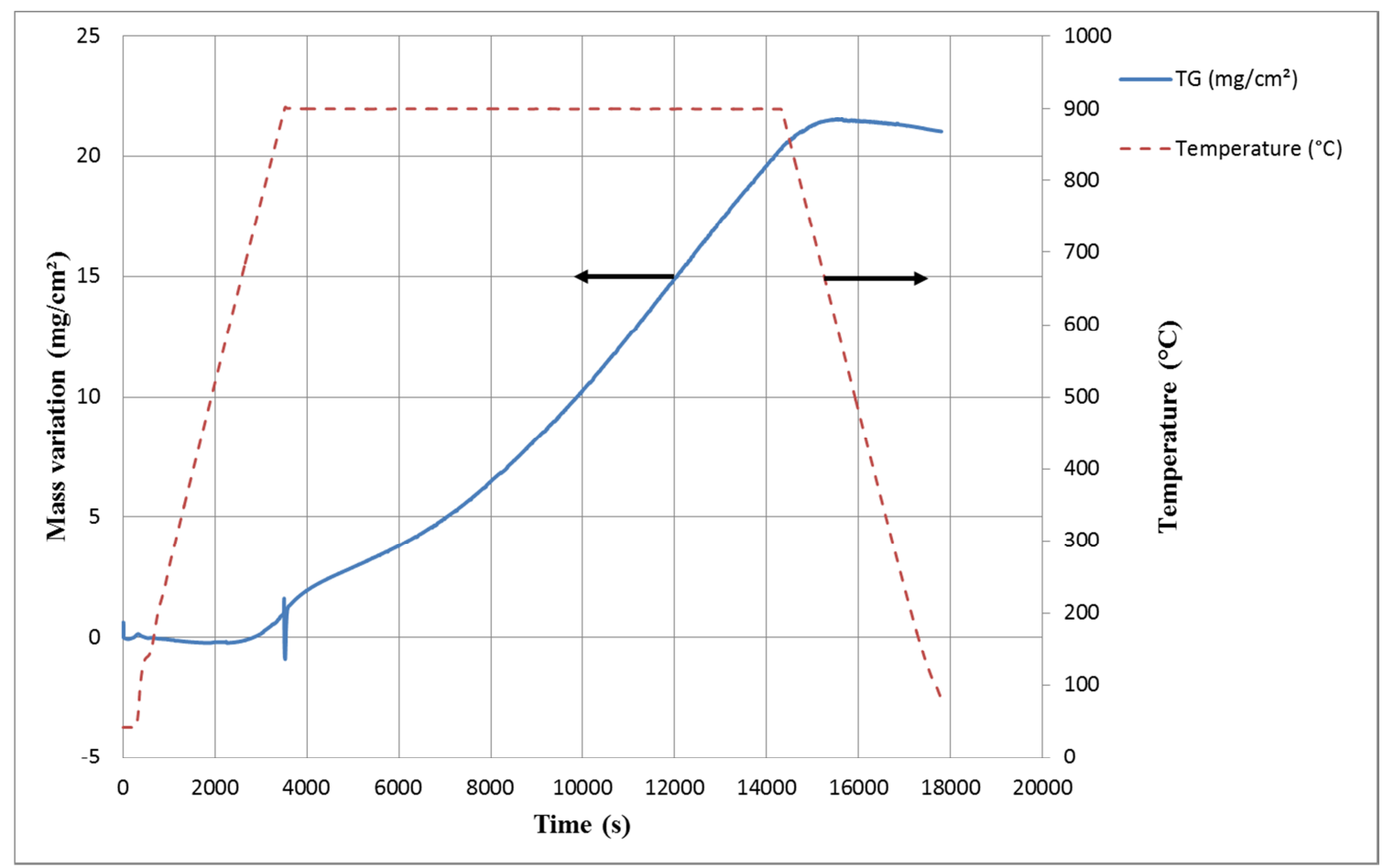

Fig.2. Mass variation $\left(\mathrm{mg} / \mathrm{cm}^{2}\right)$ as a function of time (s) and temperature variation during Zircaloy-4 oxidation test 


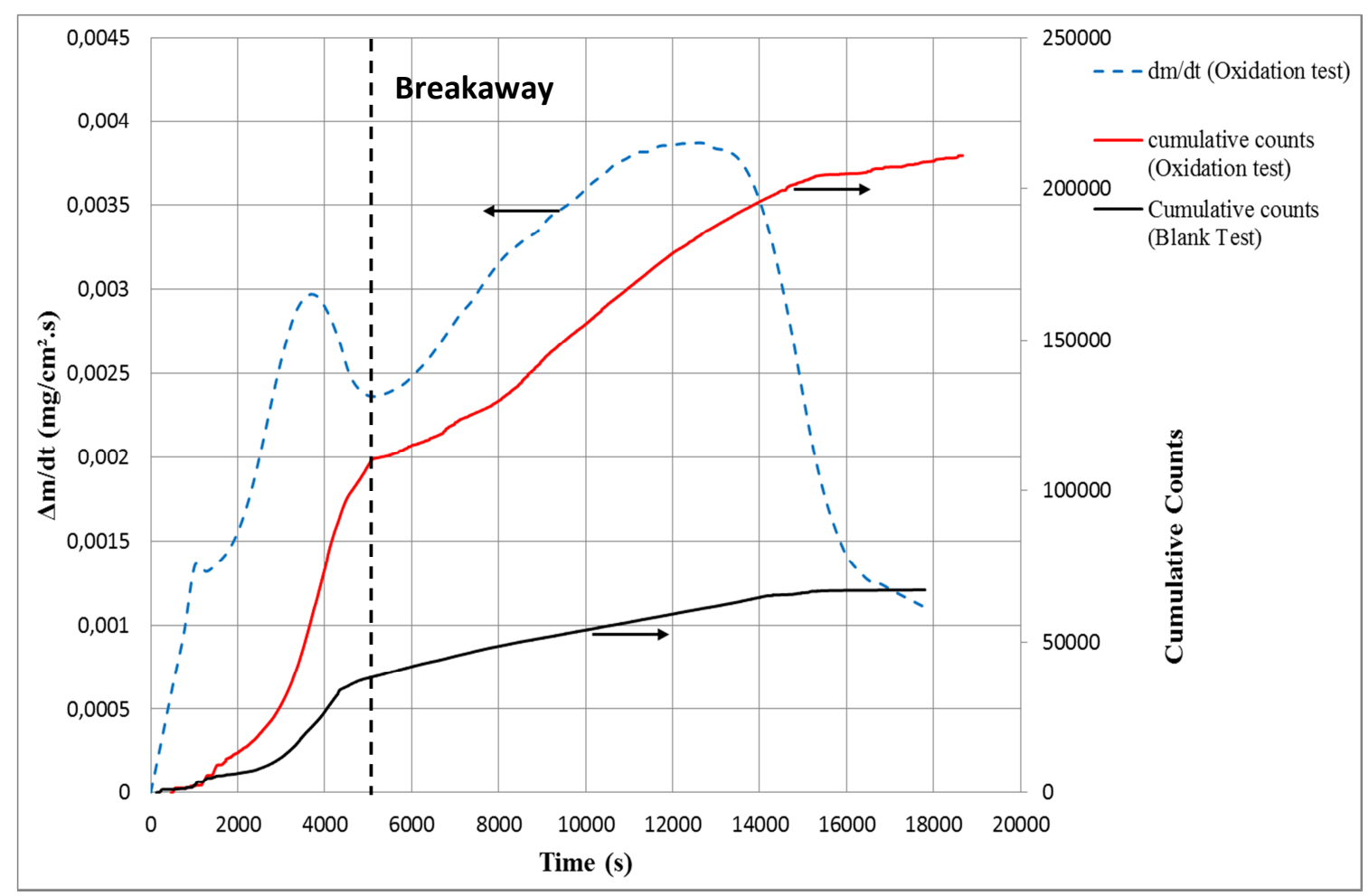

Fig.3. Mass gain rate $\left(\mathrm{mg} / \mathrm{cm}^{2} . \mathrm{s}\right)$ and cumulative counts variations during the Zircaloy- 4 oxidation and the blank test, respectively 


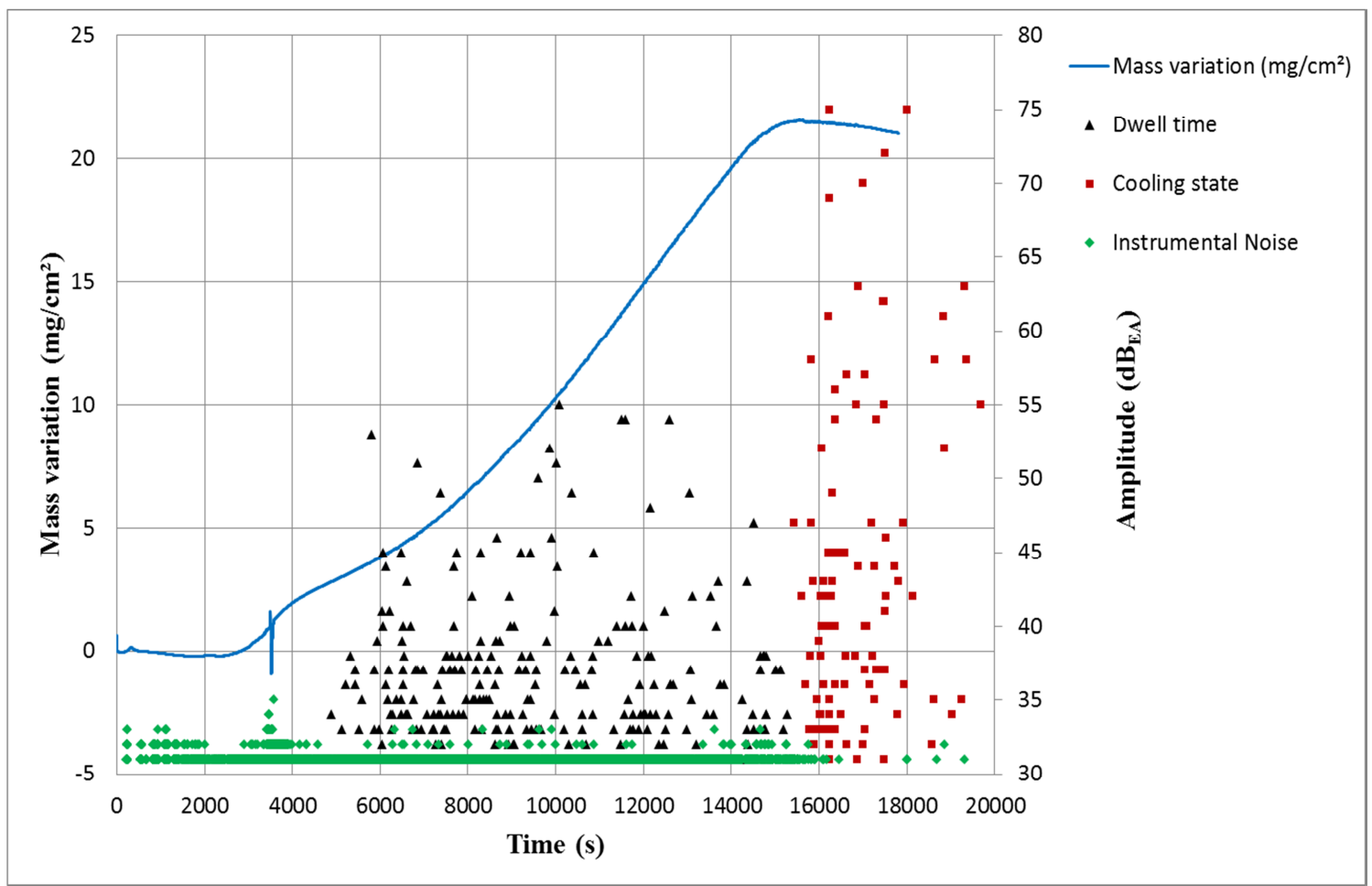

Fig.4. Mass gain and acoustic bursts amplitudes during the Zircaloy-4 oxidation test.

$(\diamond)$ Instrumental Noise, ( $\Delta$ ) Dwell time, ( $\square$ ) Cooling 


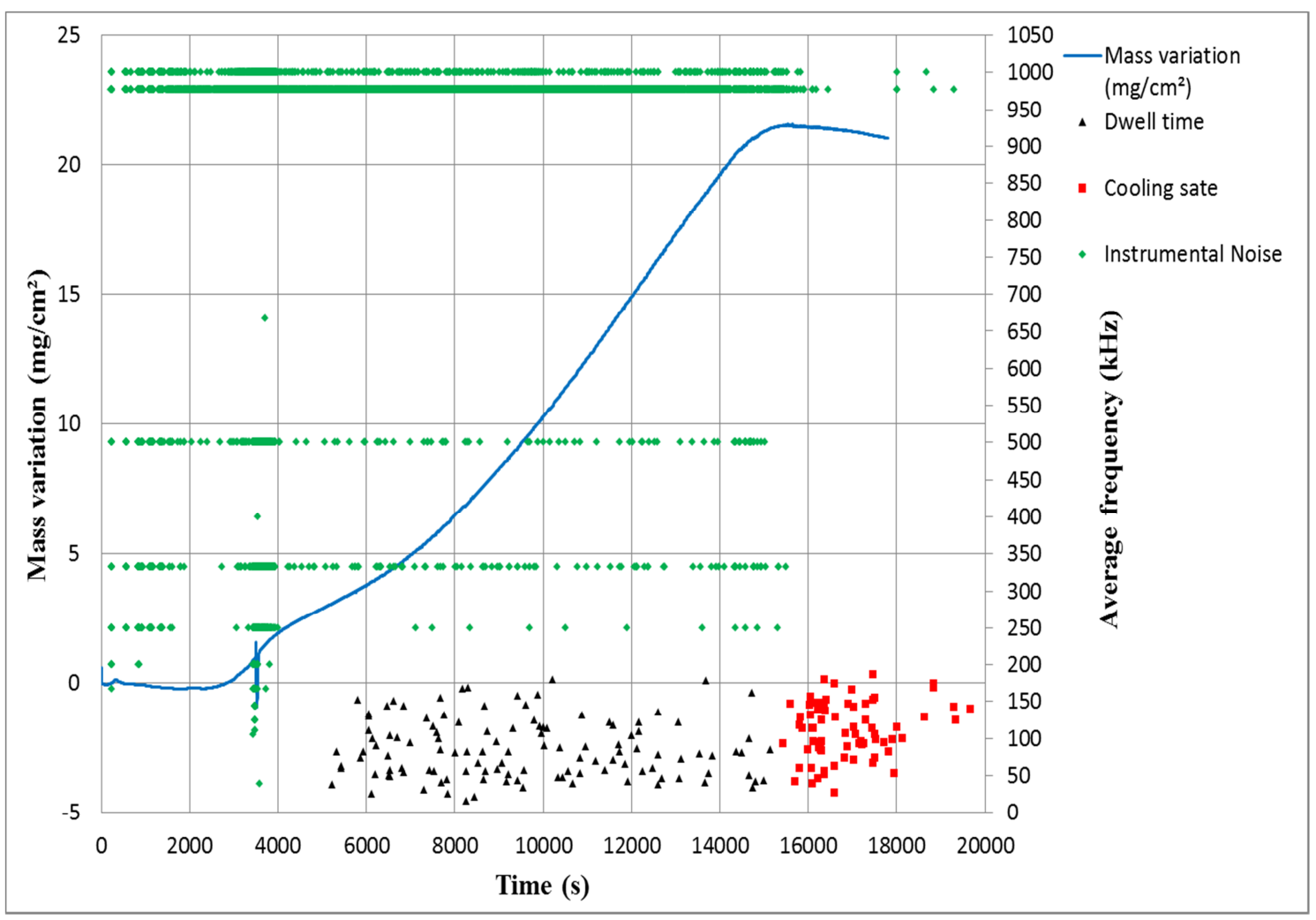

Fig.5. Mass gain and average frequency of acoustic bursts during the Zircaloy-4 oxidation test.

$(\diamond)$ Instrumental Noise, ( $\mathbf{\Delta})$ Dwell time, ( $\mathbf{\square})$ Cooling 


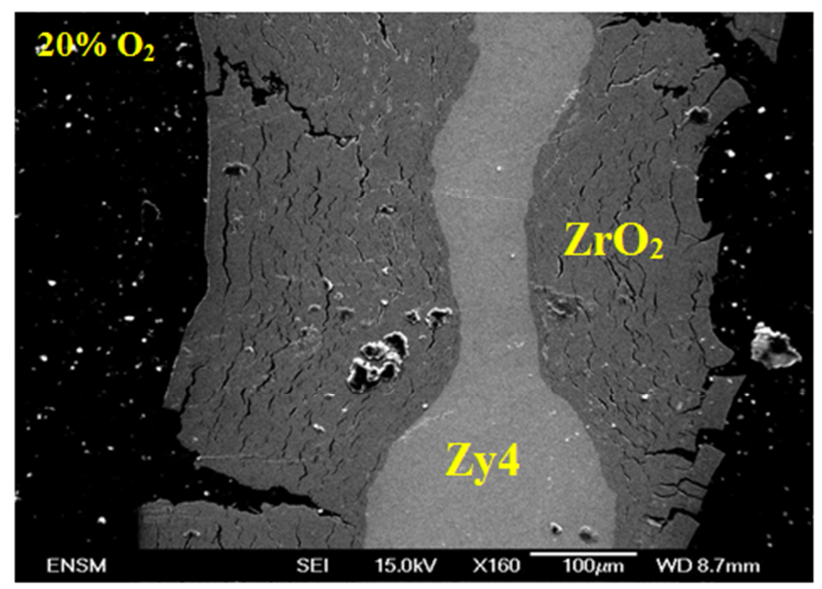

Fig.6. SEM picture of oxidized Zircaloy-4 cross section 


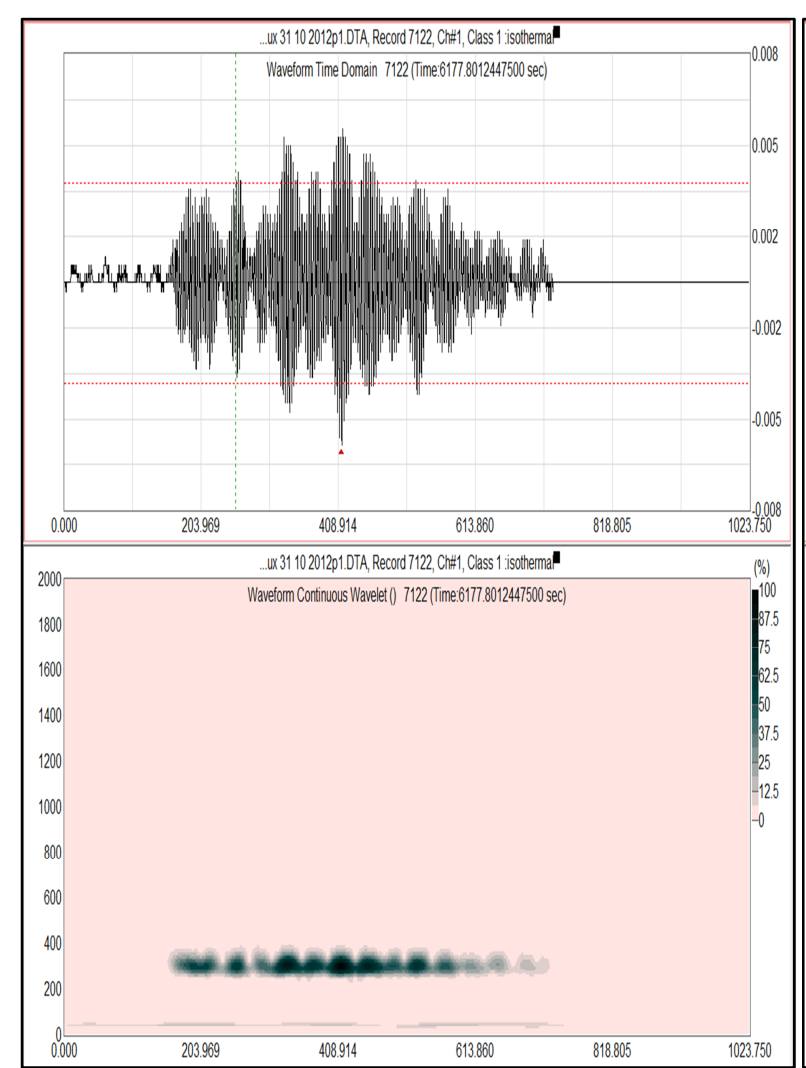

-a- Dwell time

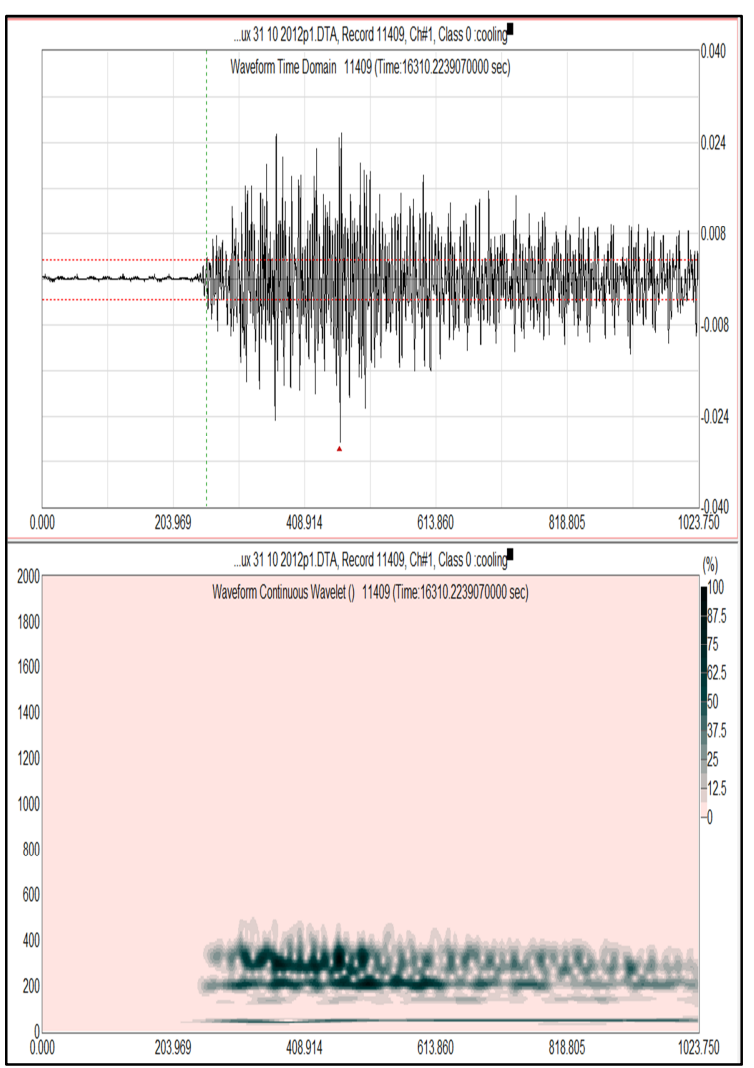

-b- Cooling

Fig.7. Typical AE burst recorded during the dwell time (a) and the cooling (b) with corresponding WT and WF. 
Tables:

Table.1. Main characteristics of the AE acquisition chain

\begin{tabular}{|c|c|c|c|c|c|}
\hline Instrumentation & Sensors & Threshold $\left(\mathbf{d B}_{\mathrm{AE}}\right)$ & $\begin{array}{c}\text { System filter } \\
(\mathbf{K H z})\end{array}$ & $\begin{array}{c}\text { Model of the } \\
\text { amplifier }\end{array}$ & Sampling rate \\
\hline Characteristics & PICO 30 & $25-30$ & $10-1200$ & $2 / 4 / 6$ gain : & $0.25 \mu \mathrm{s}(4 \mathrm{MHz})$ \\
& & & & $40 \mathrm{~dB}_{\mathrm{AE}}$ & \\
\hline
\end{tabular}


Table.2. Chemical analysis of zircaloy-4 samples

\begin{tabular}{|c|c|c|c|c|}
\hline $\mathrm{Zr}$ & $\mathrm{Sn}$ & $\mathrm{Fe}$ & $\mathrm{Cr}$ & $\mathrm{Hf}$ \\
\hline $98.23 \%$ & $1.45 \%$ & $0.21 \%$ & $0.1 \%$ & $0.01 \%$ \\
\hline
\end{tabular}


Table.3. The parameters of acoustic signals recorded during the tests

\begin{tabular}{|c|c|c|c|c|c|}
\hline Acoustic Bursts & $\begin{array}{c}\text { Amplitude } \\
\qquad\left(\mathbf{d B}_{\mathrm{AE}}\right)\end{array}$ & $\begin{array}{c}\text { Absolute Energy } \\
\text { (aJ) }\end{array}$ & $\begin{array}{c}\text { Duration } \\
\qquad(\mu \mathrm{s})\end{array}$ & Counts & $\begin{array}{c}\text { Average frequency } \\
(\mathbf{k H z})\end{array}$ \\
\hline $\begin{array}{c}\text { Instrumental Noise } \\
\text { (IN) }\end{array}$ & $30-33$ & 0 - 1 & $1-4$ & $1-2$ & $300-1000$ \\
\hline Dwell time $\left(900{ }^{\circ} \mathrm{C}\right)$ & $32-55$ & $1-2000$ & $5-2500$ & $1-350$ & $5-200$ \\
\hline $\begin{array}{c}\text { Cooling } \\
\left(\mathbf{T}<\mathbf{7 0 0}^{\circ} \mathrm{C}\right)\end{array}$ & $32-75$ & $10-2 \times 10^{5}$ & $10-7000$ & $1-1000$ & $5-175$ \\
\hline
\end{tabular}

